\title{
Comparison of Episodic Memory in Students Suffering with Cerebral Palsy and Normal Students (Original paper)
}

\section{Mousavi (Shokoufeh Mousavi)ㄹ, A. Aghayousefi (Alireza Aghayousefi)1, S. M. Zadehhossein (Sayed Mohsen Zadehhossein)1, E. Honejani (Esmail Honejami)², N. Mirjahanian (Nooshim Mirjahanian)3}

${ }^{1}$ Department of Psychology, Payame Noor University, Tehran, Iran

\section{Original Article}

2 Master of Science in Psychology, Department of Education, Isfahan, Iran

${ }^{3}$ Department of Psychology, Khomeinishahr Branch, Islamic Azad University, Khomeinishahr/Isfahan, Iran

\section{E-mail address:}

rooyamousavi@gmail.com

\section{Reprint address:}

Shokoufeh Mousavi

Department of Psychology, Payame Noor University

PO BOX 19395-3697

Tehran, Iran

Suource: Clinical Social Work and Health Intervention

Volume: 8

Issue: 3

Pages: $21-27$

Cited references: 22

\section{Reviewers:}

Roberto Cauda

Institute of Infectious Diseases, Catholic University of the Sacred Heart, Rome, IT

Steve Szydlowski

University of Scranton School of Education, USA

\section{Key words:}

Episodic memory, Verbal memory, Practical memory, Cerebral palsy, Students.

\section{Publisher:}

International Society of Applied Preventive Medicine i-gap

CSWHI 2017; 8(3): 21 - 27; DOI 10.22359/cswhi_8_3_04 @ 2017 Clinical Social Work and Health Intervention

\section{Abstract:}

The present study aimed to compare the episodic memory among students who suffer cerebral palsy and normal students. A total of 36 students participated in this study. At first, in a convenience sampling 
method 18 ill students were selected. Then 18 normal students were matched with them by demographic features, socio-economic status and average grades. For assessment of episodic memory verbal task and subject performed task were applied. Memory was evaluated by free recall test. The result of T-test and ANOVA showed there was significant difference between cerebral palsy students and the normal ones in memory tasks. Cerebral palsy students showed low and weak performance in verbal and practical memory tests. Motor weakness and speech disorders are causal factors in reducing cognitive abilities of children affected by cerebral palsy. In this aspect, reduced cognitive capacity causes those child to not have enough ability to explore the surrounding world. In this respect damaged memory assumes an important part of cognitive functioning.

\section{Introduction}

Cerebral palsy is defined as a non-progressive disorder in a growing brain. This disorder causes the occurrence of motor, conditional and neurological disabilities in the growing child (Rogers, 2005). This occurs in early years of life during the formative stages of the brain, and in fact, it is one of the most common disabilities in children the prevalence of which is 1 to 3.2 cases in each 1000 livebirths (Toopchizadeh et al., 2008).

We can find various causes for cerebral palsy including genetic, congenital, metabolic, inflammatory, infection and hypoxia (Weierink et al., 2013). All children with cerebral palsy suffer from a kind of brain lesion which usually includes motor paths. Although the defect of the motor and condition of the body are two of the main specifications of Cerebral Palsy. There are numerous secondary disorders in this field such as cognitive, sensory, mental, social defects and these disorders are different depending on the type and intensity of the cortical involvement (Pellegrino, 2002).

To date, researches on children suffering from cerebral palsy have mostly focused on their movement; but there are evidences that the symptoms of cerebral palsy exceed motor disorders and this has been accepted as a part of these disorders (Rosenbaum et al., 2007). These motor disorders are mostly together with cognitive and behavioral disabilities and sensory performance (Bottcher, 2010). The problem faced by these children more than others is establishing social relationships with their peers (Whittingham et al., 2010).

Researches have shown that the motor defect of the children suffering from cerebral palsy will ultimately negatively affect all of the aspects of their growth (Litosh, 2002). One of the most important of these aspects is memory.

By reviewing newer texts associated with memory, it was shown that today, no conceptual definition of memory as a general component is considered by the Specialists as much as the past, but each of its different types is considered as a separate definition. Generally, memory is learning information through encoding, accumulation and recovery. Encoding means putting information in memory; accumulation is keeping information in time; recovery means taking out the saved information (Santrock, 2001). 
Memory has been divided into various types such as long-term memory versus short-term memory, active memory, semantic memory, emotional memory, etc. and episodic memory is one type of long-term memory (Movahed Abtahi, 2010).

Episodic memory is one's cautious memory of the events as episodes of their lives such as their 16th birthday party, falling off a bike and what they have had for breakfast today. Episodic memory is in fact memory of remembering (Sousa, 2006). This type of personal memory is mixed with emotions and is detailed. The main feature in episodic memory is that it is associated with a specific moment in time; not with any time or the entire time but with the time the one experiences themselves (Convey, 2008). Recent studies show that episodic memory is self-awareness as a continuous existence in time and the possibility of a mental cautious experience (Soderlund et al., 2008).

Peters, et al. (2009), in a study, aimed to review growth of reading skill in children suffering from cerebral palsy and to compare them with ordinary children and showed that children suffering from cerebral palsy, with additional speaking disorders, encounter more risks in the field of growth of this skill.

Hulk, et al. (2011), in a study, reviewed the ability of expression of events and occurrences as one of the vital abilities in doing everyday activities and expressing personal experiences which can be considered as a part of episodic memory and showed that children with cerebral palsy have been weaker than ordinary children in this area.

Khayatzadeh Mahani, et al. (2011), in a study, aimed to investigate the problems children with cerebral palsy face and showed that speaking difficulties experience the highest rate of problems among these children. They also showed that there is a significant relationship between the level of motor function and mental and speech problems, eating, seizures and the number of accompanying problems.

In Iran, many researches have been done in the field of cerebral palsy and the disorders it brings, but there is not much information about the difference between the episodic memory of ordinary and ill children and few studies have been done in this regard. Thus, this study attempts to compare and investigate the speech and performance memory of students suffering from these disorders and compare them with ordinary children. Research hypotheses is as follows:

1. Students with cerebral palsy are different from normal students in verbal memory,

2. Students with cerebral palsy are different from normal students in practical memory,

3. Verbal memory in students with cerebral palsy is different from their practical memory.

\section{Research Method}

The research method in this study has been a comparative causal method and 36 middle school and high school students have participated. In order for the sampling, at first the researcher visited Taha School for people with physical and motor disabilities in Isfahan and 18 of their students with cerebral palsy were selected through the method at hand (the number of all of the students suffering with cerebral palsy at that academic year was 25 persons some of whom had severe disabilities and were not able to do the physical assignments of this study and that is why they were not selected). Then, given the age, gender, socio-economic condition and average of the group 
of students, the group of the ordinary samples (18 persons) were matched with them $(\mathrm{P}>0.60)$.

\section{Episodic memory test}

In this study, the episodic memory test included 32 short imperative sentences selected based on the study of Karami Noori and Mousavi (2008). 32 sentences were divided into two 16-sentence lists and each of them were used for verbal and practical memory. In order to do the episodic memory tests, after presenting the instructions and some examples, the person is asked to do some assignments and after the list is finished, in order to create a distance between the stages of encoding and accumulation, the semantic memory test was done. The reason for the creation of this distance was for the long-term learning memory to be formed for the testees.

In order for the students not to use practical strategies in speech encoding, the speech list was what was presented to the testees first. In the speech-related assignment, some sentences are read to the testees and they must repeat them and memorize them. After presenting a speech list and creating an approximately 30-minute distance during which the testees received the semantic memory test, the free accumulation test was done during which a white sheet is given to them and they are asked to write down any number of sentences that they remember in their order of preference. Then, the second list of the sentences is given to them and they must do the assignment with the tools given to them at the same time after hearing the sentences. After finishing the list and a 30-minute time difference (receiving semantic memory tests), the testees again receive a sheet associated with free accumulation.

Each test taken by an individual took about 150 minutes for each testee. It was attempted to provide a peaceful, and quiet environment without traffic. The scoring here was done in such a way that if the testee remembered the original sentence, he or she was given the score one.

\section{Results}

Mean and standard deviation of task of two groups of cerebral palsy and normal students are shown in Table $\mathbf{1 .}$

Table 1: Descriptive characteristics (mean and standard deviation) of providing task

\begin{tabular}{|l|l|l|l|}
\hline Types of Memory & Number & Mean & SD \\
\hline Verbal memory & 18 & 2.44 & 1.10 \\
\hline Student with cerebral palsy & 18 & 3.66 & 1.05 \\
\hline Normal students & 18 & 6.11 & 1.11 \\
\hline Practical memory & 18 & 7.88 & 1.31 \\
\hline Student with cerebral palsy & \multicolumn{5}{l}{} \\
\hline Normal students &
\end{tabular}

Table 2: Results of t test between the two groups in the verbal task

\begin{tabular}{|l|l|l|l|}
\hline Index & T & df & Two-tailed significance \\
\hline Verbal & -2.295 & 34.000 & 0.036 \\
\hline
\end{tabular}


Table 3: Results of $\mathrm{t}$ test between the two groups in the practical task

\begin{tabular}{|l|l|l|l|}
\hline Index & T & df & Two-tailed significance \\
\hline Practical & -3.094 & 34.000 & 0.007 \\
\hline
\end{tabular}

Results of t test between the two groups are shown in Table 2 and $\mathbf{3}$. According to the results there was a significant difference between the two groups of cerebral palsy and normal students, so that testee with cerebral palsy had a lower performance than normal students. ANOVA analysis was also performed to ensure more, where there is a significant difference. Summary of ANOVA for both verbal and practical task are shown in Tables 4 and 5.
7.88 respectively; which difference between the two groups was significant at the Table $3(\mathrm{sig}=0.007$ and $\mathrm{t}=-3.094)$. Generally, the results showed higher mean scores in both practical and verbal memory in normal students.

The obtained results comply with the findings of Peters, et al. (2009), Hulk, et al. (2011), Khayatzadeh Mahani, et al. (2011) in the presence of disorders in motor and

Table 4: Summary of ANOVA for the scores of testee in verbal task

\begin{tabular}{|l|l|l|l|l|l|}
\hline Sources of changes & SS & df & MS & F & Sig \\
\hline Between group & 6.126 & 1 & 6.125 & - & - \\
\hline Intergroup & 18.611 & 34 & 1.163 & 5.266 & 0.036 \\
\hline Total & 24.736 & 35 & - & - & - \\
\hline
\end{tabular}

Table 5: Summary of ANOVA for the scores of testee in practical task

\begin{tabular}{|l|l|l|l|l|l|}
\hline Sources of changes & SS & df & MS & F & Sig \\
\hline Between group & 14.222 & 1 & 14.222 & - & - \\
\hline Intergroup & 23.778 & 34 & 1.486 & 9.570 & 0.000 \\
\hline Total & 38.000 & 35 & - & - & - \\
\hline
\end{tabular}

\section{Discussion and conclusion}

The aim of the study was to investigate the differences between verbal and practical memory in students with cerebral palsy and normal students. The results of this study in Table 1 showed that average verbal memory in testees with cerebral palsy and normal students was 2.44 and 3.66 respectively, which difference between the two groups was significant in Table 2 ( $\mathrm{sig}=0.036$ and $\mathrm{t}=-2.295)$. The results also showed average practical memory in testees with cerebral palsy and normal students was 6.11 and cognitive functions in people suffering from cerebral palsy in comparison with ordinary people.

Motion is considered to be one of the most important needs in the natural growth of human beings. Therefore, doing basic motor skills such as crawling, walking and jumping is very satisfying for a child. However, children who lack these motor capabilities are deprived from such a blessing (Baloochi and Ghaeni, 2009). Presence of a disorder in various functions of the motor 
system of the children suffering from cerebral palsy causes reduction of the working capacities of their upper organs and ultimately limits their environmental capabilities and social compliance (Symivnova, 1999).

The evidences at hand show that more disorders in the functional and cognitive function of these people might create some problems in their social participation and educational potentials (Bottcher, et al. 2010). The functional performance includes various behaviors including control; planning for motion; starting behavior; response inhibition (Collette, et al. 2006). This disorder weakens the function of the person in the practical memory test in comparison with ordinary people.

Pirila, et al. (2007) believed that most children suffering from cerebral palsy also suffer from speech disorders and this problem might be due to motor disorders. Speech disorders are seen in more than $80 \%$ of the children suffering from cerebral palsy (Odding et al., 2006). Prevalence of these disorders has a significant relationship with the type and intensity of motor involvement (Shevell et al., 2009). The delay in cognitive growth and lower than average IQ is seen in $50 \%$ to $75 \%$ of these children. These disorders can vary from mild to severe (Odding et al., 2006). Also, 15\% to $60 \%$ of these children also suffer from seizure and epilepsy and when this disease comes along with epilepsy provides the substrate for cognitive defects (Khodapanahandeh, 2004). Therefore, the presence of cognitive disorders leads to the reduction of the function of the person suffering from cerebral palsy in speech memory tests in comparison with ordinary people.

In an overall conclusion, it can be said that cerebral palsy, as a disease that comes with motor defect and weakness, creates the substrate for the creation of disorder in cognitive activities including memory. In other words, motor weakness in the child suffering from this disease leads to them not having the sufficient movement to explore and discover their surrounding world and as time goes by, the rate of their cognitive capacities will be reduced. Memory, as an important component of cognitive function, gets harmed in this respect. The person suffering from cerebral palsy, in comparison with a healthy person, is not able to repeat the events while doing the assignments associated with verbal and practical memory and then talk about them and repeat them. Therefore, verbal and practical memory and in total, the episodic memory of that person will be weaker than a healthy person.

Investigation of other types of memory in these individuals and comparing them with ordinary people have not been done in this study. Thus, it is recommended to the future researchers to compare these patients regarding their long-term memory, semantic memory, active memory, emotional memory and other types of memory. It is also recommended to them to do some interventions in the field of improvement of memory in these people and to investigate its effects on different types of memory.

\section{References}

1. BOTTCHER L (2010) Children with spastic cerebral palsy, their cognitive functioning, and social participation: A review. Child Neuropsychology. 16(3): 209-228.

2. BOTTCHER L, FLACHS E M, ULDALL P (2010) Attentional and executive impairments in children with spastic cerebral palsy. Developmental Medicine and Child Neurology 52(2):42-47.

3. COLLETTE F, HOGGE M, SALMON E,. VAN DER LINDEN M (2006) Exploration of the neural substrates of executive 
functioning by functional neuro imaging, Neuroscience. 139(1): 209-221.

4. CONVEY M A (2008) Exploring episodic memory. Dere E A, Easton, A, Nadel L (eds). Handbook of Episodic Memory, Elsevier: UK.

5. KARAMI NOORI R, MOUSAVI S (2008) Compare variety of episodic and semantic memory in deaf and hearing students. Recent Cognitive Science. 10 (4): 83-93.

6. KHAYATZADEH MAHANI M, AMIRSALARI S, KARIMLOO M (2011) Investigating the problems of children with cerebral palsy and their relation to the type and level of motor function. Journal of Medicine. 10(1): 59-67.

7. KHODAPANAHANDEH F (2004) Epilepsy in children with cerebral palsy, Iranian journal of Medical Sciences. 11(43): 743-748.

8. LITOSH L (2002) Adaptive physical education-psychological characteristics education of children with growth disorders. Public Sport Academy Press Moscow. pp. 225-29.

9. MOVAHED ABTAHI M (2010) Studies acute effects of nicotine on spatial learning and memory in rats using a radial arm maze. Clinical psychology master's thesis, Faculty of Education and Psychology, University of Isfahan. Iran.

10. ODDING E, ROEBROECK M E, STAM H $\mathrm{J}$ (2006) The epidemiology of cerebral palsy: incidence, impairments and risk factors, Disability Rehabil. 28(4): 183-191.

11. PELLEGRINO L (2002) Cerebral Palsy. In: Batshaw ML editor. Children with disabilities. Baltimore: Brookes; pp: 443-466.

12. PIRILA S, VAN DER MEERE J, PENTIKAINEN T, RUUSU-NIEMI P, KORPELA R, KILPINEN J (2007) Language and motor speech skills in children with cerebral palsy. Journal of Communication Disorders. 40: 116-128.

13. ROGERS S (2005) Common conditions influencing children's participation. In:
Case-Smith J. Occupational therapy for children.5th ed. Boston: Mosby Co. 176-80.

14. ROSENBAUM P, PANETH N, LEVITON A, GOLDSTEIN M, BAX M, DAMIANO D (2007) A report: The definition and classification of cerebral palsy April 2006. Developmental Medicine and Child Neurology. Supplement. 109: 8-14.

15. SANTROCK J W (2001) Educational Psychology. Publisher: McGraw-Hill. ISBN: 0072906367.

16. SHEVELL M I, DAGENAIS L, HALL N (2009) Co-morbidities in cerebral palsy and their relationship to neurologic subtype and GMFCS level, Neurology. 72(24): 20902096.

17. SODERLUND H, BLACK S E, MILLER B L, FREEDMAN M., LEVINE B (2008) Episodic memory and regional atrophy in frontotemporal lobar degeneration, Neuropsychological. 46:127-136.

18. SOUSA D A (2006) How the Brain Learns, Sage publication: India.

19. SYMIVNOVA A (1999) Reconstructive treatment in children with cerebral palsy. Publ Ntydvr Moscow. Pp.165-69.

20. TOOPCHIZADEH V, BARZEGAR M H, HOSSEINI S M J (2008) Reviews the type of cerebral palsy, etiology, associated disorders and motor development in children's hospital in Tabriz. Medical Journal of Tabriz University of Medical Sciences. 30(4): 27-31.

21. WEIERINK L, VERMEULEN R J, BOYD R N (2013) Brain structure and executive functions in children with cerebral palsy: A systematic review, Research in Developmental Disabilities. 34: 1678-1688

22. WHITTINGHAM K, FAHEY M, RAWICKI B, BOYD R (2010) The relationship between motor abilities and early social development in a preschool cohort of children with cerebral palsy, Research in Developmental Disabilities. 31(6): 1346-1351. 